\title{
Effect of Speech Stimulus, Gender, and Age on Phonation Threshold Measures in Korean Adults
}

\author{
Ju Eun Park ${ }^{1,2}$, Seong Hee Choi ${ }^{2,3}$, Kyoung Jae Lee ${ }^{2,3}$, Chul-Hee Choi ${ }^{2,3}$ \\ ${ }^{1}$ Beautiful Voice Clinic, Seoul, Korea \\ ${ }^{2}$ Department of Audiology and Speech-Language Pathology, Graduate School of Daegu Catholic University, Gyeongsan, Korea \\ ${ }^{3}$ Department of Audiology and Speech-Language Pathology, Research Institute of Biomimetic Sensory Control, \\ and Catholic Hearing Voice Speech Center, Daegu Catholic University, Gyeongsan, Korea
}

한국 성인의 발성역치 측정치의 자극어, 성별, 연령의 효과

박주은 ${ }^{1,2} \cdot$ 최성희 ${ }^{2,3} \cdot$ 이경재 ${ }^{2,3} \cdot$ 최철희 ${ }^{2,3}$

아름다운 목소리 이비인후과 ${ }^{1}$, 대구가톨릭대학교 일반대학원 언어청각치료학과 ${ }^{2}$, 대구가톨릭대학교 바이오메디대학 언어청각치료학과, 생체모방감각제어연구소, 가톨릭 청각음성언어센터 ${ }^{3}$

\begin{abstract}
Purpose: The purpose of this study was to examine phonation threshold measures of Korean adults and examine their effects of age, gender, and speech stimulus. Methods: A total of 120 Korean adults (males 60, females 60) from the 20s to 50 s participated in this study. For measuring phonation threshold measures, phonation threshold pressure (PTP) and phonation threshold flow (PTF) were measured using the Phonatory Aerodynamic System (PAS) Model 6600 (KayPENTAX Corp.) and phonation threshold power (PTW) was calculated from PTP and PTF. Results: The results showed that PTF and PTP values were significantly different according to gender $(p<0.05)$; significantly higher PTF and PTP values were revealed in males. On the other hand, PTW values were significantly different in age and gen$\operatorname{der}(p<0.05)$. Moreover, significant effect on speech stimulus (/pa/ vs. /pi/) was observed in PTP $(p<0.001)$ and PTW ( $p<0.001)$. Higher PTP and PTW were estimated with /pi/. Conclusion: Accordingly, these results demonstrated PTF and PTP had a gender effect suggesting that phonation threshold related aerodynamic measures should take into consideration for gender. Additionally, PTP and PTW measures were also changed depend upon speech stimulus. Thus, speech stimulus also should be considered in measuring PTP and unified speech stimulus need to provide for evaluating aerodynamic measures more effectively in clinical practice.
\end{abstract}

Key Words: Phonation threshold flow, Phonation threshold pressure, Phonation threshold power, Age, Gender.

Received: May 10, 2019 / Revised: July 17, 2019 / Accepted: July 18, 2019

Correspondence: Seong Hee Choi, Department of Audiology and Speech-Language Pathology, Research Institute of Biomimetic Sensory Control, and Catholic Hearing Voice Speech Center, Daegu Catholic University, 13-13 Hayang-ro, Hayang-eup, Gyeongsan 38430, Korea

Tel: +82-53-850-2542 / Fax: +82-53-359-6780 / E-mail: shgrace@cu.ac.kr

\section{INTRODUCTION}

정상 음성을 산출하기 위해서는 호흡, 발성, 공명의 상호작용 이 중요하다. 음성 산출은 흡기 시 들숨 작용으로 적절한 폐압 을 형성하고 날숨 작용으로 후두 쪽으로 기류의 흐름을 만들 어 성대를 적절한 힘으로 좁혀주는 기류 작용과 이 기류가 성

(c) This is an Open Access article distributed under the terms of the Creative Commons Attribution Non-Commercial License (https://creativecommons.org/licenses/by-nc/4.0) which permits unrestricted non-commercial use, distribution, and reproduction in any medium, provided the original work is properly cited.
대를 지나면서 조절 과정을 거치는 발성 과정을 통해 이루어진 다. 즉, 호흡은 발성의 에너지원으로서 음성 산출을 위해 성대 를 진동시키는 최소한의 압력을 생성하며, 발성은 성대 조직의 탄력과 공기역학적인 힘의 상호관계로 이루어진다(Titze, 1992; Van den Berg, 1958). 공기역학적 평가는 발성 시 성대의 근탄성 력과 성문을 통과하는 공기의 속도, 압력과 양 등을 측정하는 데, 발성 시 공기를 조절하여 사용하는 개인의 능력을 반영하여 성대의 병리적 양상, 진동 양상, 접촉 양상 등을 예측할 수 있고 치료 전후의 효과를 비교할 수 있어 임상에서 청지각적 평가, 음 
향학적 평가와 함께 일반적으로 사용되는 음성평가법 중 하나이 다. 공기역학적 특징을 살펴본 선행연구(Choi et al., 2000; Lee et al., 2015b; Suh et al., 1999; Suh et al., 2006; Zheng et al., 2012)에 따르면, 공기역학적 측정 매개 변수는 정상 음성과 병 리적 음성을 판정할 뿐만 아니라 수술 전후 그리고 치료 전후 의 성대 기능에 대한 변화를 살펴보는 데 효과적이었으며, 공기 역학적 검사 항목으로는 최장발성지속시간(maximum phonation time), 성문하압(subglottal pressure, Psub), 평균호기류율 (mean flow rate, MFR), 성문저항(glottal resistence), 음성효 율(vocal efficiency, VE) 측정치가 주로 사용되었다. 공기역학 적 평가를 위한 기기인 Aerophone II (Kay Elemetrics Corp., Lincoln Park, NJ, USA)는 단종된 상태이며, 현재 임상에서는 Phonatory Aerodynamic System (PAS, Model 6600, KayPENTAX Corp., Lincoln Park, NJ, USA)이 주로 사용되고 있 다. 국내외 연구 중 정상인을 대상으로 공기역학적 평가 파라미 터 기준을 제시한 연구는 Aerophone II를 이용한 Suh et al. (1997)과 Park et al.(2001)이 있으며, 최근에는 PAS를 이용하여 정상인을 대상으로 한 연구가 보고되었으나, VE나 maximum phonaiton 과제를 이용한 공기역학적 측정 파라미터 연구가 대 부분이다(Choi \& Choi, 2014; Kim, 2014; Zraick et al., 2012).

한편, 발성역치기류(phonation threshold flow, PTF)는 발성 역치압력(phonation threshold pressure, PTP)과 함께 비침습 적으로 측정이 가능한 새로운 공기역학 측정치이다. PTF는 성 대 진동을 시작하기 위해 요구되는 최소한의 기류를 나타내며, $\mathrm{PTP}$ 는 소리를 산출하기 위해 성대를 진동시키는 최소한의 성 문하압으로 두 측정치 모두 성대의 생체역학적 특성을 제공해주 는 지표로서 간주되고 있다. Phonation threshold power (PTW) 는 성대 진동 시작과 소리를 산출하기 위한 최소한의 능력을 말 하는 것으로, PTF와 PTP의 곱으로 산출되어 기류와 압력에 관 한 특징을 모두 반영하여 가장 민감한 지표로 보고되고 있다 (Titze, 1992; Zhuang et al., 2013).

Jiang \& Tao(2007)의 연구에서 PTF는 임상 환경에서 후두 기능장애를 변별하는 민감하고 강력한 도구로 보고하였으며, Zhuang et al.(2009)의 연구에서는 21명의 성대결절 환자와 23 명의 성대용종 환자 및 성과 연령을 일치시킨 정상 대조군 40 명을 대상으로 공기역학검사를 실시한 결과, PTF와 MFR이 모 두 정상 음성과 병리학적 음성을 감별하는 데 높은 민감도를 나 타내어 양성 성대병변 진단에 도움을 줄 수 있다고 하였다. 또한 Choi et al.(2010)의 연구에서도 31명의 내전형 연축성 발성장애 여성과 연령을 일치시킨 16 명의 정상 여성군을 대상으로 PTF와 $\mathrm{PTP}$ 를 측정한 결과, $\mathrm{PTP}$ 는 정상 대조군과 내전형 연축성 발성 장애 환자군과 유의한 차이를 보이지 않았으나, PTF는 두 집 단 간 유의한 차이를 보여 감별 진단에 유용한 것으로 나타났으
며, 내전형 연축성 발성장애 환자군 내 중증도를 민감하게 감별 하는 것으로 나타났다. Zhuang et al.(2013)의 연구에서도 19명 의 성대마비 환자와 94 명의 양성 성대병변 환자, 100 명의 정상 대 조군을 대상으로 발성역치 측정치를 비교한 결과 PTP와 PTF 는 각 음성장애에 대해 민감도가 높은 유용한 공기역학적 파라 미터였으며, PTW도 성대운동장애 판별에 민감하며 음성 생성 을 위한 공기역학적 입력을 설명하는 유용한 파라미터임을 보 고하였다. 국내에서는 PTF와 PTP 매개 변수를 내전형 경련성 발성장애군과 정상군 간에 비교하여 내전형 경련성 발성장애의 증상과 중증도 판별에 민감한 지표임을 보고한 Choi et al.(2010) 의 연구와 음성장애군과 정상군을 비교한 Lee et al.(2013)의 연 구, 그리고 갑상선 수술 후 기능적 음성장애에서 PTP의 유용함 을 보고한 Lee et al.(2015a)의 연구가 있으나, 국내 정상 성인의 연령과 성별 및 자극어에 따른 발성역치 측정치 연구가 전무한 실정이다.

또한 발성역치압력의 측정에서 방법론적인 면은 정확한 공기 역학적 측정치를 얻는 데 결정적이며 중요한 요소인데, 공기역 학적 측정 기기인 PAS 매뉴얼에서는 Voicing Efficiency 프로 토콜로 성문하압을 측정할 때 자극어 $/ \mathrm{pa} /$ 를 사용하도록 제시 되어 있으나, 최근 American Speech-Language-Hearing Association에서 제시한 평가 가이드라인에서는 자극어 $/ \mathrm{pi}$ 를 이 용하도록 제안하고 있다(Patel et al., 2018). 따라서 측정 시 검 사어의 차이에 대한 증거 기반이 부족한 실정이며, 이와 더불어 국내에서는 아직까지 검사어에 대한 통일된 기준의 프로토콜이 없는 실정이다. Aerophone II를 이용한 Park et al.(2001)의 선 행연구에 따르면 모음 $/ \mathrm{a} /$ 와 / $\mathrm{i} /$ 의 변화에 따라 성문하압에 유의 한 차이가 있었고, 성문하압과 강도의 상관관계가 있었음이 보 고되어 이에 대한 증거 마련이 필요함을 알 수 있다. 하지만 자 극어 선택의 타당성에 대한 연구는 여전히 미약한 수준이며 $\mathrm{PAS}$ 를 이용한 공기역학적 측정치의 국내 연구는 아직 이루어 지지 않았다.

따라서 본 연구에서는 최근 임상에서 활발히 사용하는 공기 역학적 측정 기기인 PAS를 이용하여 발성에 관여하는 호흡의 공기역학적 생리의 비정상을 판별하고 치료 효과를 예측하는 데 민감한 지표인 발성역치의 국내 정상 성인의 성별과 연령 및 자극어에 따른 차이와 강도를 살펴보고 이를 기반으로 정상 기 준치를 마련하기 위해 고려해야 할 요소들을 살펴보고자 한다.

\section{MATERIALS AND METHODS}

\section{연구 대상}

연구에 참여한 대상자는 정상 한국 성인 총 120 명(남자 60 명, 여자 60명)으로 평균 연령은 $38.5( \pm 12.4)$ 세이며, 연령과 성별에 
따른 대상자 정보는 Table 1에 제시하였다.

본 연구에 포함된 정상인 대상자의 선정은 건강 상태를 확인 하기 위한 설문지와 신체 계측치 측정을 통해 1) 한국인 평균 신장과 체중 범위에 속하는 자, 2) 신경계질환, 갑상선질환, 호흡 기질환, 인지적 결함 및 조음기관과 청력의 문제가 없는 자, 3) 이 비인후과 음성평가실에서 3년 이상 임상 경력이 있는 언어재활 사 2인의 평가로 청지각적 평가 (GRBAS 척도 중 $\mathrm{G})$ 에서 0점인 자를 포함하고, 4) 주당 20갑 이상 흡연, 주당 $200 \mathrm{~g}$ 이상 음주 하는 경우에는 대상자에서 제외함을 기준으로 하였다(Kim, 2014; Kim et al., 2010). 또한 여성 대상자의 경우 월경 주기에 따른 호르몬의 변화가 있지만, 음성의 음향학적, 공기역학적 지 표에 변화가 없었음이 보고되어 선정 기준에 포함하지 않았다 (Lee et al., 2008).

\section{연구 절차}

\section{검사의 실시 절차 및 방법}

공기역학적 측정 도구인 PAS (Model 6600)를 이용하여 선 행연구 방법을 따라 측정하였다.

$\mathrm{PTF}$ (발성역치기류) 측정

$\mathrm{PTF}$ 측정은 1 분당 $40 \mathrm{~dB}$ 이하의 소음이 통제된 방에서 $\mathrm{PAS}$
를 이용한 공기역학적 검사 중 Maximum Sustained Phonation 프로토콜을 이용하여 측정하였다. 연구자는 대상자에게 의자 에 반듯하게 앉아 마스크를 착용한 뒤 부드러운 강도로 /a/ 발 성을 시작하여 3 초에서 5 초 안에 발성이 들리지 않을 때까지 점차 강도를 감소시키도록 요구하였고, 이를 위해 3회 정도 연 습을 한 후 10 회 측정하였다. 선행연구에서 PTF 분석 기준 시 점을 대략 sound pressure level $50 \mathrm{~dB}$ 로 함과 같이 본 연구의 분석 기준에도 적용하였으며, 10 회의 평균값을 비교 분석하였 다(Figure 1, 2) (Choi et al., 2010; Zhuang et al., 2009, 2013).

PTP (발성역치압력) 측정

$\mathrm{PTP}$ 측정은 PAS 프로토콜 중 Voicing Efficiency를 이용하 여 $/ \mathrm{pa} /$ 와 $/ \mathrm{pi}$ / 자극어에 따른 PTP를 측정하였다. 대상자에게 공 기 누출을 차단하기 위한 마스크를 착용하도록 하고 직경 $2 \mathrm{~mm}$ 이내의 구강튜브를 입술 사이에 위치시켜 이 튜브를 물거나 혀 로 막지 않도록 하였다. 그리고 한 호기에 기식음이 아닌 가장 부드럽고 최소한의 강도로 연속하여 발성할 수 있도록 3회 정 도 연습을 한 뒤 $/ \mathrm{pa}, \mathrm{pa}, \mathrm{pa}, \mathrm{pa}, \mathrm{pa} /$ 를 초당 1.5 음절의 속도로 모음 부분을 명확하게 발성하도록 하여 측정하였다. 측정한 값 은 처음과 마지막 음절을 제외한 가운데 세 음절의 평균을 비 교 분석하여 $\mathrm{PTP}$ 의 값을 산출했고, $\mathrm{dB}$ 데이터를 함께 분석하 였다. $/ \mathrm{pi}$ / 자극어에 대해서도 이와 같은 방법으로 측정하였다

Table 1. Demographic information of the participants $(n=120)$ as a function of four age groups

\begin{tabular}{cccccc}
\hline Age group & Gender & Number of subject & Mean age & Height $(\mathrm{cm})$ & Weight $(\mathrm{kg})$ \\
\hline $20 \mathrm{~s}$ & $\mathrm{M}$ & 15 & $24.0 \pm 2.2$ & $174.6 \pm 4.3$ & $73.1 \pm 8.2$ \\
& $\mathrm{~F}$ & 15 & $21.2 \pm 2.0$ & $160.3 \pm 4.7$ & $54.2 \pm 4.0$ \\
$30 \mathrm{~s}$ & $\mathrm{M}$ & 15 & $33.4 \pm 2.5$ & $174.7 \pm 4.5$ & $74.9 \pm 8.4$ \\
& $\mathrm{~F}$ & 15 & $33.7 \pm 3.0$ & $162.7 \pm 3.1$ & $55.2 \pm 8.0$ \\
$40 \mathrm{~s}$ & $\mathrm{M}$ & 15 & $44.5 \pm 3.2$ & $173.3 \pm 5.2$ & $74.4 \pm 5.2$ \\
& $\mathrm{~F}$ & 15 & $43.7 \pm 2.7$ & $159.7 \pm 5.3$ & $55.0 \pm 7.7$ \\
\multirow{2}{*}{$50 \mathrm{~s}$} & $\mathrm{M}$ & 15 & $53.3 \pm 3.1$ & $169.6 \pm 4.4$ & $69.2 \pm 7.4$ \\
& $\mathrm{~F}$ & 15 & $53.9 \pm 3.2$ & $157.7 \pm 5.8$ & $59.0 \pm 7.8$ \\
\hline
\end{tabular}

M: male, F: female

Figure 1. Measurement of phonation threshold flow for a male participant using Phonatory Aerodynamic System.

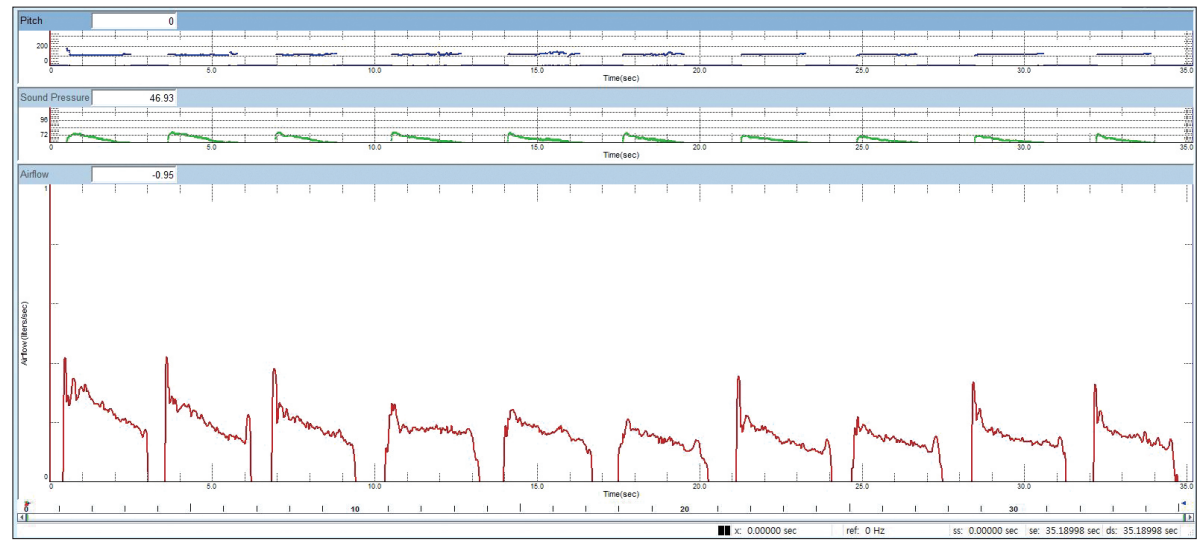




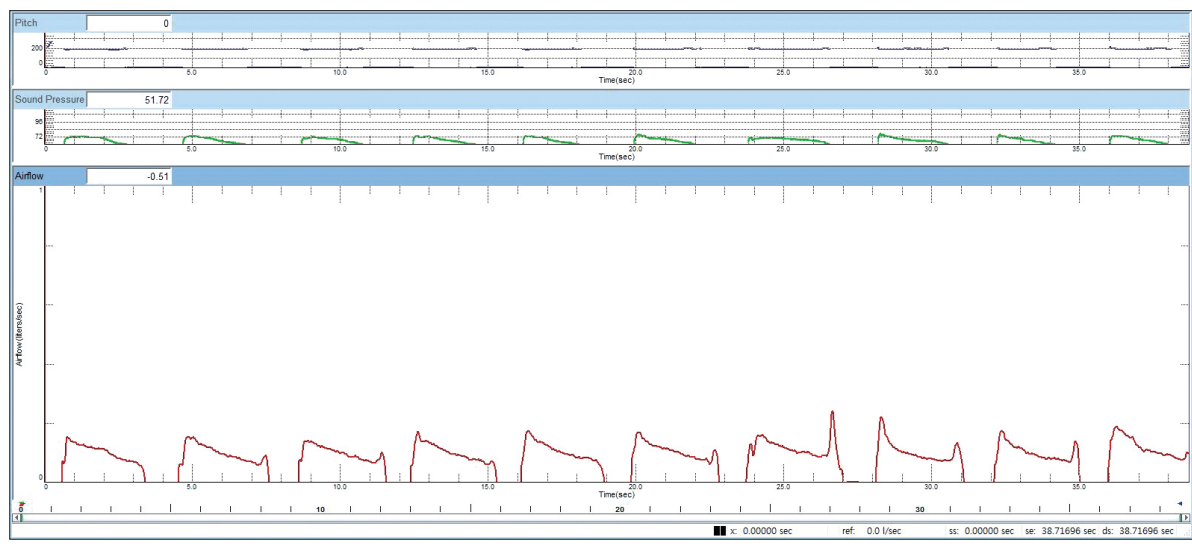

Figure 2. Measurement of phonation threshold flow for a female participant using Phonatory Aerodynamic System.

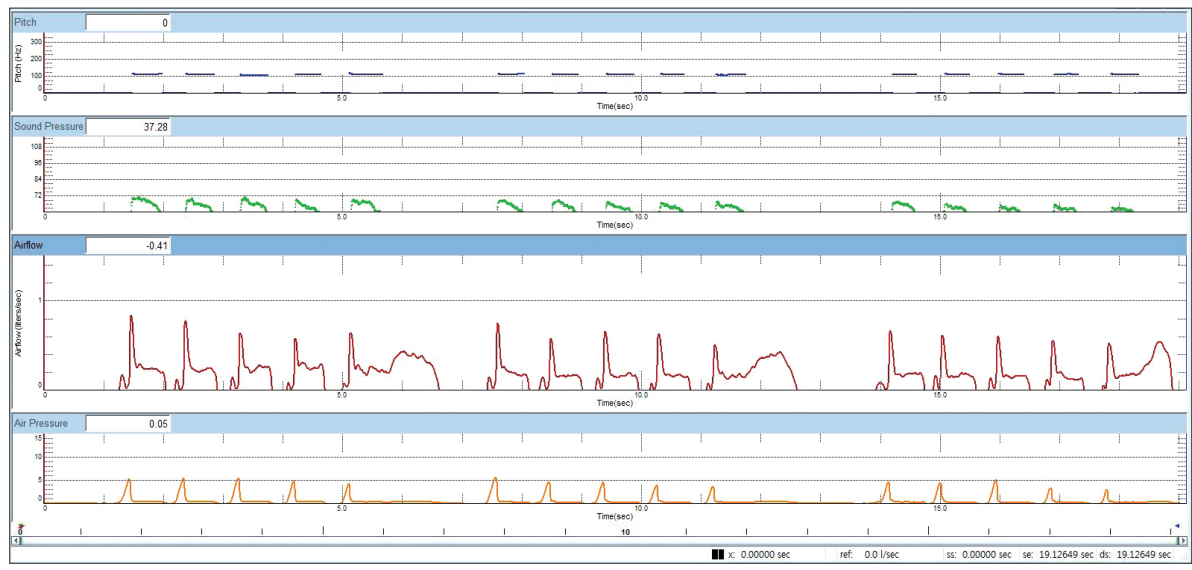

Figure 3. Measurement of phonation threshold pressure spoken by stimulus /pa/ for a male participant using Phonatory Aerodynamic System.

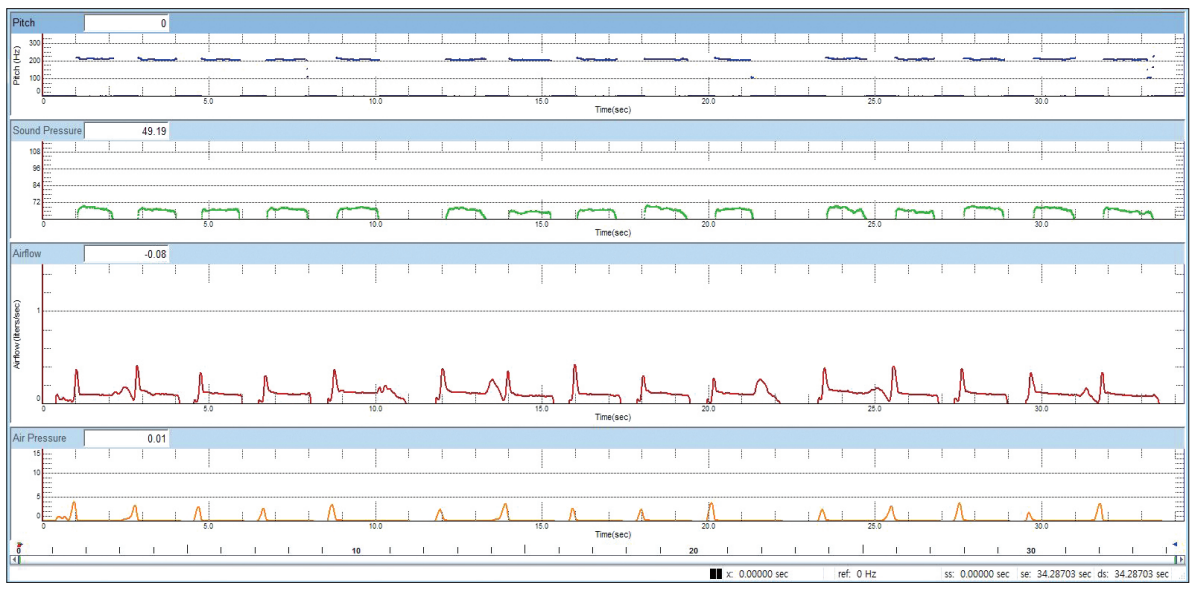

Figure 4. Measurement of phonation threshold pressure spoken by stimulus /pi/ for a male participant using Phonatory Aerodynamic System.

(Figure 3, 4) (Choi et al., 2010; Zhuang et al., 2009, 2013).

$\mathrm{PTW}$ (발성역치력) 측정

$\mathrm{PTW}$ 는 $\mathrm{PTF}$ 와 $\mathrm{PTP}$ 의 곱으로 이루어지므로 $\mathrm{PTF}$ 와 $\mathrm{PTP}$ 의 값을 이용해 산출했다(Titze et al., 1988; Zhuang et al., 2013).

$\mathrm{PTW}=\mathrm{PTF} \times \mathrm{PTP}$

\section{자료 및 통계 분석}

통계분석은 SPSS software (Ver. 19.0, IBM corp., Armonk, $\mathrm{NY}, \mathrm{USA}$ )를 이용하였다. 성별과 연령에 따른 발성역치 측정치 에 유의한 차이가 있는지 검증하기 위해 이원분산분석(twoway ANOVA)을 실시하였다. 자극어에 따른 발성역치 측정치 에 유의한 차이가 있는지 검증하기 위해 대응표본 $t$ 검정 (paired $t$-test)을 실시하였다. 유의수준은 $95 \%$ 로 하였다. 


\section{RESULTS}

\section{성별과 연령에 따른 발성역치 측정치 비교}

\section{성별과 연령에 따른 PTF 비교}

정상 성인의 성별과 연령에 따른 $\mathrm{PTF}$ 측정치의 평균과 표준 편차는 Table 2와 같다. 20대 정상 성인의 경우 남성 $0.147( \pm$ $0.089) \mathrm{L} / \mathrm{sec}$, 여성은 $0.049( \pm 0.034) \mathrm{L} / \mathrm{sec}$ 로 남성의 PTF 값 이 높았다. 30 대의 경우 정상 성인 남성의 PTF 값은 $0.189( \pm$ $0.081) \mathrm{L} / \mathrm{sec}$, 여성은 $0.050( \pm 0.042) \mathrm{L} / \mathrm{sec}$ 로 남성의 PTF 값이 높았다. 40대에서는 정상 성인 남성의 PTF 값은 0.201( \pm 0.086$)$ $\mathrm{L} / \mathrm{sec}$, 여성은 $0.055( \pm 0.065) \mathrm{L} / \mathrm{sec}$ 로 남성의 PTF 값이 높았 다. 50대의 경우 정상 성인 남성의 PTF 값은 $0.227( \pm 0.063) \mathrm{L} /$ $\mathrm{sec}$, 여성은 $0.059( \pm 0.034) \mathrm{L} / \mathrm{sec}$ 로 남성의 PTF 값이 높았다. 전체 정상 성인 남성의 PTF 값은 $0.191( \pm 0.083) \mathrm{L} / \mathrm{sec}$, 정상 성 인 여성의 PTF 값은 $0.053( \pm 0.044) \mathrm{L} / \mathrm{sec}$ 로 남성의 PTF 값 이 높았다. 20대에서 50대 모두 여성보다 남성의 PTF 값이 높 았다.

성별과 연령에 따른 PTF 측정치의 평균값의 차이를 살펴보 기 위해 이원분산분석을 실시하였다. 분석 결과 성별과 연령 간 상호작용은 유의하지 않았고 $[\mathrm{F}(3,112)=1.497, p=0.219]$, 연령의 주 효과 또한 통계적으로 유의하지 않았으나 $[\mathrm{F}(3,112)=$ $2.416, p=0.070], \mathrm{PTF}$ 에 대한 성별의 주효과는 통계적으로 유 의한 차이를 보였다 $[\mathrm{F}(1,112)=133.027, p<0.001]$ (Table 3).

Table 2. Comparison of gender and age in PTF measure

\begin{tabular}{ccc}
\hline Age & Gender $(\mathrm{n}=120)$ & PTF $(\mathrm{L} / \mathrm{sec})$ \\
\hline $20 \mathrm{~s}$ & $\mathrm{M}(\mathrm{n}=15)$ & $0.147 \pm 0.089$ \\
& $\mathrm{~F}(\mathrm{n}=15)$ & $0.049 \pm 0.034$ \\
$30 \mathrm{~s}$ & $\mathrm{M}(\mathrm{n}=15)$ & $0.189 \pm 0.081$ \\
& $\mathrm{~F}(\mathrm{n}=15)$ & $0.050 \pm 0.042$ \\
$40 \mathrm{~s}$ & $\mathrm{M}(\mathrm{n}=15)$ & $0.201 \pm 0.086$ \\
& $\mathrm{~F}(\mathrm{n}=15)$ & $0.055 \pm 0.065$ \\
$50 \mathrm{~s}$ & $\mathrm{M}(\mathrm{n}=15)$ & $0.227 \pm 0.063$ \\
\multirow{2}{*}{ Total } & $\mathrm{F}(\mathrm{n}=15)$ & $0.059 \pm 0.034$ \\
& $\mathrm{M}(\mathrm{n}=60)$ & $0.191 \pm 0.083$ \\
& $\mathrm{~F}(\mathrm{n}=60)$ & $0.053 \pm 0.044$ \\
\hline
\end{tabular}

PTF: phonation threshold flow, M: male, F: female
성별과 연령에 따른 PTP 비교

정상 성인의 성별과 연령에 따른 $\mathrm{PTP}$ 측정치의 평균과 표준 편차는 Table 4와 같다. 20대 정상 성인 남성의 PTP 값은 $3.851( \pm 0.959) \mathrm{cmH}_{2} \mathrm{O}$, 여성은 3.538( \pm 0.466$) \mathrm{cmH}_{2} \mathrm{O}$ 로 남성 의 PTP 값이 높았다. 30 대의 정상 성인 남성의 PTP 값은 4.089 $( \pm 1.008) \mathrm{cmH}_{2} \mathrm{O}$, 여성은 3.693( \pm 1.128$) \mathrm{cmH}_{2} \mathrm{O}$ 이고, 40대 의 경우 정상 성인 남성의 PTP 값은 4.239 $( \pm 0.962) \mathrm{cmH}_{2} \mathrm{O}$, 여성은 4.005( \pm 1.117$) \mathrm{cmH}_{2} \mathrm{O}$ 이며, 50대의 경우 정상 성인 남 성의 PTP 값은 4.609 $( \pm 0.881) \mathrm{cmH}_{2} \mathrm{O}$, 여성은 4.072( \pm 0.993) $\mathrm{cmH}_{2} \mathrm{O}$ 로 20대에서 50대 모든 연령에서 남성의 PTP 값이 높 았다. 전체 정상 성인 남성의 PTP 값은 4.197( \pm 0.970) $\mathrm{cmH}_{2} \mathrm{O}$, 여성은 3.827 $( \pm 0.966) \mathrm{cmH}_{2} \mathrm{O}$ 였다.

이원분산분석을 이용하여 성별과 연령에 따른 PTP 측정치 의 차이를 살펴보았을 때 성별과 연령 간 상호작용은 유의하지 않았고 $[\mathrm{F}(3,112)=0.136, p=0.938], \mathrm{PTP}$ 에 대한 연령의 주 효 과도 통계적으로 유의한 차이를 보이지 않았으나 $[\mathrm{F}(3,112)=$ 2.561, $p=0.059$ ], $\mathrm{PTP}$ 에 대한 성별의 주 효과에서 통계적으로 유의한 차이를 보였다 $[\mathrm{F}(1,112)=4.459, p<0.05]$ (Table 5).

\section{성별과 연령에 따른 PTW 비교}

정상 성인의 성별에 따른 PTW 측정치의 평균과 표준편차는 Table 6과 같다. 20대의 경우 남성의 PTW 값은 0.579( \pm 0.406) $\mathrm{cmH}_{2} \mathrm{O} \mathrm{L} / \mathrm{sec}$, 여성의 PTW 값은 $0.170( \pm 0.102) \mathrm{cmH}_{2} \mathrm{O} \mathrm{L} / \mathrm{sec}$ 이고, 30 대의 경우 남성의 PTW 값은 $0.736( \pm 0.337) \mathrm{cmH}_{2} \mathrm{O} \mathrm{L/}$ $\mathrm{sec}$, 여성의 PTW 값은 $0.178( \pm 0.142) \mathrm{cmH}_{2} \mathrm{O} \mathrm{L} / \mathrm{sec}$ 였으며,

Table 4. Comparison of gender and age in PTP measure

\begin{tabular}{ccc}
\hline Age & Gender $(\mathrm{n}=120)$ & PTP $\left(\mathrm{cmH}_{2} \mathrm{O}\right)$ \\
\hline $20 \mathrm{~s}$ & $\mathrm{M}(\mathrm{n}=15)$ & $3.851 \pm 0.959$ \\
& $\mathrm{~F}(\mathrm{n}=15)$ & $3.538 \pm 0.466$ \\
$30 \mathrm{~s}$ & $\mathrm{M}(\mathrm{n}=15)$ & $4.089 \pm 1.008$ \\
& $\mathrm{~F}(\mathrm{n}=15)$ & $3.693 \pm 1.128$ \\
$40 \mathrm{~s}$ & $\mathrm{M}(\mathrm{n}=15)$ & $4.239 \pm 0.962$ \\
& $\mathrm{~F}(\mathrm{n}=15)$ & $4.005 \pm 1.117$ \\
$50 \mathrm{~s}$ & $\mathrm{M}(\mathrm{n}=15)$ & $4.609 \pm 0.881$ \\
& $\mathrm{~F}(\mathrm{n}=15)$ & $4.072 \pm 0.993$ \\
Total & $\mathrm{M}(\mathrm{n}=60)$ & $4.197 \pm 0.970$ \\
& $\mathrm{~F}(\mathrm{n}=60)$ & $3.827 \pm 0.966$ \\
\hline
\end{tabular}

PTP: phonation threshold pressure, M: male, F: female

Table 3. Statistical results of PTF by gender and age groups

\begin{tabular}{lccccc}
\hline & Type III sum of squares & $\mathrm{df}$ & Mean square & $\mathrm{F}$ & $p$-value \\
\hline Age & 0.031 & 3 & 0.010 & 2.416 & 0.070 \\
Gender & 0.567 & 1 & 0.567 & 133.027 & $0.000^{*}$ \\
Gender $\times$ age & 0.019 & 3 & 0.006 & 1.497 & 0.219 \\
\hline
\end{tabular}

${ }^{*} p<0.001$. PTF: phonation threshold flow 
Table 5. Statistical results of PTP by gender and age groups

\begin{tabular}{lccccc}
\hline & Type III sum of squares & $\mathrm{df}$ & Mean square & $\mathrm{F}$ & p-value \\
\hline Age & 7.068 & 3 & 2.356 & 2.561 & 0.059 \\
Gender & 4.103 & 1 & 4.103 & 4.459 & $0.037^{*}$ \\
Gender $\times$ age & 0.377 & 3 & 0.126 & 0.136 & 0.938 \\
\hline
\end{tabular}

${ }^{*} p<0.05$. PTP: phonation threshold pressure

Table 6. Comparison of gender and age in PTW measure

\begin{tabular}{ccc}
\hline Age & Gender $(\mathrm{n}=120)$ & PTW $\left(\mathrm{cmH}_{2} \mathrm{O} \mathrm{L} / \mathrm{sec}\right)$ \\
\hline $20 \mathrm{~s}$ & $\mathrm{M}(\mathrm{n}=15)$ & $0.579 \pm 0.406$ \\
& $\mathrm{~F}(\mathrm{n}=15)$ & $0.170 \pm 0.102$ \\
$30 \mathrm{~s}$ & $\mathrm{M}(\mathrm{n}=15)$ & $0.736 \pm 0.337$ \\
& $\mathrm{~F}(\mathrm{n}=15)$ & $0.178 \pm 0.142$ \\
$40 \mathrm{~s}$ & $\mathrm{M}(\mathrm{n}=15)$ & $0.836 \pm 0.406$ \\
& $\mathrm{~F}(\mathrm{n}=15)$ & $0.211 \pm 0.206$ \\
$50 \mathrm{~s}$ & $\mathrm{M}(\mathrm{n}=15)$ & $1.067 \pm 0.398$ \\
& $\mathrm{~F}(\mathrm{n}=15)$ & $0.238 \pm 0.139$ \\
Total & $\mathrm{M}(\mathrm{n}=60)$ & $0.804 \pm 0.418$ \\
& $\mathrm{~F}(\mathrm{n}=60)$ & $0.200 \pm 0.150$ \\
\hline
\end{tabular}

PTW: phonation threshold power, M: male, F: female

40대의 경우 남성의 PTW 값은 0.836 \pm 0.406$) \mathrm{cmH}_{2} \mathrm{O} \mathrm{L} / \mathrm{sec}$, 여성의 PTW 값은 $0.211( \pm 0.206) \mathrm{cmH}_{2} \mathrm{O} \mathrm{L} / \mathrm{sec}, 50$ 대의 경우 남성의 PTW 값은 $1.067( \pm 0.398) \mathrm{cmH}_{2} \mathrm{O} \mathrm{L} / \mathrm{sec}$, 여성의 PTW 값은 0.238( \pm 0.139) $\mathrm{cmH}_{2} \mathrm{O} \mathrm{L} / \mathrm{sec}$ 로 모든 연령대에서 남성의 PTW 값이 높았다. 전체 성별과 연령에 따른 정상 성인 남성의 $\mathrm{PTW}$ 값은 $0.804( \pm 0.418) \mathrm{cmH}_{2} \mathrm{O} \mathrm{L} / \mathrm{sec}$, 여성의 PTW 값은 $0.200( \pm 0.150) \mathrm{cmH}_{2} \mathrm{O} \mathrm{L} / \mathrm{sec}$ 였다.

이원분산분석을 이용하여 성별과 연령에 따른 PTW 측정치 의 차이를 살펴보았을 때 성별과 연령 간 상호작용은 유의하지 않았다 $[\mathrm{F}(3,112)=2.624, p=0.054]$. PTW에 대한 연령의 주 효 과는 통계적으로 유의한 차이를 보였고 $[\mathrm{F}(3,112)=4.769, p<$ $0.01]$, 성별의 주 효과도 통계적으로 유의한 차이를 보였다 $[\mathrm{F}(1$, 112) $=126.514, p<0.001$ (Table 7). 연령에 따른 차이를 알아 보기 위해 Tukey 사후검정 결과 20대와 50대에서 유의한 차이 를 보였다 $(p<0.01)$ (Table 8).

\section{자극어에 따른 발성역치 측정치 비교}

\section{자극어에 따른 PTP 비교}

정상 성인의 자극어 $/ \mathrm{pa} /$ 의 PTP 값은 4.012( \pm 0.090) $\mathrm{cmH}_{2} \mathrm{O}$ 이고, 자극어 /pi/의 PTP 값은 4.429 $( \pm 0.090) \mathrm{cmH}_{2} \mathrm{O}$ 로 자극어 $/ \mathrm{pi} /$ 의 측정치가 높았다(Table 9 ).

대응표본 $t$ 검정을 이용하여 자극어에 따른 PTP의 평균값의 차이를 살펴본 결과 통계적으로 유의한 차이를 보였다 $[t(119)=$ $-6.578, p<0.001]$ (Table 10).

\section{자극어에 따른 PTW 비교}

정상 성인의 자극어 $/ \mathrm{pa} /$ 의 PTW 값은 $0.502( \pm 0.040) \mathrm{cm}^{-}$ $\mathrm{H}_{2} \mathrm{O} \mathrm{L} / \mathrm{sec}$ 이고, 자극어 /pi/의 PTW 값은 $0.557( \pm 0.044)$ $\mathrm{cmH}_{2} \mathrm{O} \mathrm{L} / \mathrm{sec}$ 로 자극어 /pi/의 측정치가 높았다(Table 11).

대응표본 $t$ 검정을 이용하여 자극어에 따른 PTW의 평균값 의 차이를 살펴본 결과 통계적으로 유의한 차이를 보였다 $[t(119)=-5.483, p<0.001]$ (Table 12).

자극어에 따른 강도 $(\mathrm{dB})$ 비교

정상 성인의 자극어 $/ \mathrm{pa} /$ 의 강도 값은 $68.996( \pm 0.281) \mathrm{dB}$, 자극어 $/ \mathrm{pi} /$ 의 강도값은 $68.922( \pm 0.288) \mathrm{dB}$ 로 자극어 $/ \mathrm{pa} /$ 의 강도값이 높았으나(Table 13), 대응표본 $t$ 검정을 이용하여 자극 어에 따른 강도의 평균값의 차이를 살펴본 결과 통계적으로 유 의한 차이를 보이지 않았다 $[t(119)=0.380, p=0.705]$ (Table 14).

\section{DISCUSSIONS}

본 연구는 병리학적 음성의 공기역학적 기능을 측정하는 데 매우 민감한 지표로 보고되는 발성역치 측정치의 정상 규준치 마련을 위한 예비연구로서 20대에서 50대의 한국 정상 성인을 대상으로 발성역치 측정치를 분석하여 비교하였으며 성별과 연 령 및 자극어의 영향을 조사하였다.

\section{성별과 연령에 따른 발성역치 측정치 비교}

본 연구 결과 PTF는 성별에서 유의한 차이를 보였으며 $(p<$ 0.001), 모든 연령대에서 남성이 여성과 비교해 높은 측정치를 보였다. 반면에 PTF 측정치는 연령이 증가함에 따라 증가하였 으나 통계적으로 유의한 차이는 없었다. 이러한 결과는 국외 연 구에서 PTF 측정치에 성별 간 유의한 차이가 있음이 보고된 Zhuang et al.(2009)의 연구와 국내 선행연구에서 남성의 PTF 가 여성보다 높음을 보고하는 Lee et al.(2013)의 연구와 유사 한 결과이다. 한편 국내에서는 Kim(2014)과 Suh et al.(1997)의 연구에서 공기역학적 기류 지표인 평균호기류율이 남성이 여성 에 비해 더 높음을 보고하여 발성 시 평균호기류율이 성별 간 유의한 차이를 나타낸다고 하였다. 하지만 아직까지 국내에서 PTF에 대한 연구가 매우 미흡한 상태이므로 본 연구 결과와 비교할 수 있는 자료가 매우 부족한 실정이며 발성역치 측정치 
Table 7. Statistical results of PTW by gender and age groups

\begin{tabular}{lcccrr}
\hline & Type III sum of squares & df & Mean square & F & p-value \\
\hline Age & 1.241 & 3 & 0.414 & 4.769 & $0.004^{*}$ \\
Gender & 10.974 & 1 & 10.974 & 126.514 & $0.000^{\dagger}$ \\
Gender $\times$ age & 0.683 & 3 & 0.228 & 2.624 & 0.054 \\
\hline
\end{tabular}

${ }^{*} p<0.01,{ }^{\dagger} p<0.001$. PTW: phonation threshold power

Table 8. Tukey post-hoc of PTW according to age for Korean adults

\begin{tabular}{cccc}
\hline Age & Mean difference & Std. error & Tukey- $p$ \\
\hline $20 \mathrm{~s}$ & & & \\
$30 \mathrm{~s}$ & -0.083 & 0.076 & 0.699 \\
$40 \mathrm{~s}$ & -0.149 & 0.076 & 0.211 \\
$50 \mathrm{~s}$ & -0.278 & 0.076 & $0.002^{*}$ \\
$30 \mathrm{~s}$ & & & \\
$20 \mathrm{~s}$ & 0.083 & 0.076 & 0.699 \\
$40 \mathrm{~s}$ & -0.066 & 0.076 & 0.820 \\
$50 \mathrm{~s}$ & -0.195 & 0.076 & 0.055 \\
$40 \mathrm{~s}$ & & & \\
$20 \mathrm{~s}$ & 0.149 & 0.076 & 0.211 \\
$30 \mathrm{~s}$ & 0.066 & 0.076 & 0.820 \\
$50 \mathrm{~s}$ & -0.129 & 0.076 & 0.329 \\
$50 \mathrm{~s}$ & & & \\
$20 \mathrm{~s}$ & 0.278 & 0.076 & $0.002^{*}$ \\
$30 \mathrm{~s}$ & 0.195 & 0.076 & 0.055 \\
$40 \mathrm{~s}$ & 0.129 & 0.076 & 0.329 \\
\hline$* 0201 \mathrm{PTW}$ & & &
\end{tabular}

${ }^{*} p<0.01$. PTW: phonation threshold power

Table 9. Mean of PTP measurements according to stimulus

\begin{tabular}{cc}
\hline Stimulus & $\mathrm{PTP}\left(\mathrm{cmH}_{2} \mathrm{O}\right)$ \\
\hline$/ \mathrm{pa} /$ & $4.012 \pm 0.090$ \\
$/ \mathrm{pi} /$ & $4.429 \pm 0.090$ \\
\hline
\end{tabular}

PTP: phonation threshold pressure

Table 10. Comparison in PTP between two stimuli

\begin{tabular}{cccc}
\hline Stimulus & $t$ & $\mathrm{df}$ & $p$-value \\
\hline$/ \mathrm{pa} /-/ \mathrm{pi} /$ & -6.578 & 119 & $0.000^{*}$ \\
\hline
\end{tabular}

의 PTF는 평균호기류율과는 다르므로 평균호기류율과 PTF의 상관성에 대한 추가적인 연구가 필요하다.

이와 마찬가지로 성별과 연령에 따른 PTP 측정치를 비교했을 때 연령에 따른 유의한 차이는 없었으나 모든 연령에서 남성이 여성보다 높은 수치를 나타냈고 성별에 따른 유의한 차이가 있 었다 $(p<0.05)$. 정상 성인을 대상으로 성문하압을 측정한 국내 외 연구를 살펴보면 성별 간 평균 성문하압에 유의한 차이가 없음을 보고하였는데(Goozée et al., 1998; Kim, 2014; Suh et al., 1997; Zraick et al., 2012), 본 연구에서는 압력과 관련된 측 정 변수인 PTP 측정 결과 성별 간 유의한 차이를 보여, 성문하 압과 달리 발성을 위한 최소한의 압력인 발성역치압력은 성별
Table 11. Mean of PTW measurements according to stimulus

\begin{tabular}{cc}
\hline Stimulus & PTW \\
\hline$/ \mathrm{pa} /$ & $0.502 \pm 0.040$ \\
/pi/ & $0.557 \pm 0.044$ \\
\hline
\end{tabular}

PTW: phonation threshold power

Table 12. Comparison in PTW between two stimuli

\begin{tabular}{cccc}
\hline Stimulus & $t$ & $\mathrm{df}$ & $p$-value \\
\hline /pa/ - /pi/ & -5.483 & 119 & $0.000^{*}$ \\
${ }^{*} p<0.001$. PTW: phonation threshold power &
\end{tabular}

Table 13. Mean of $\mathrm{dB}$ measurements according to stimulus

\begin{tabular}{cc}
\hline Stimulus & $\mathrm{dB}$ \\
\hline$/ \mathrm{pa} /$ & $68.996 \pm 0.281$ \\
$/ \mathrm{pi} /$ & $68.922 \pm 0.288$ \\
\hline
\end{tabular}

Table 14. Comparison in dB between two stimuli

\begin{tabular}{cccc}
\hline Stimulus & $t$ & $\mathrm{df}$ & $p$-value \\
\hline$/ \mathrm{pa} /-/ \mathrm{pi} /$ & 0.380 & 119 & 0.705 \\
\hline
\end{tabular}

간 차이가 날 수 있음을 시사하였다. 따라서 본 연구 결과 PTF 와 마찬가지로 PTP도 성문하압과 어떠한 상관성이 있는지 추 후의 연구가 더 필요하다. 또한 Zraick et al.(2012)의 연구에서 는 정상 성인 157명(남자 68명, 여자 89명)을 대상으로 PAS를 이용한 공기역학적 파라미터 측정치를 분석했을 때, 평균호기 류율은 남성이 여성보다 높고 성별 간 유의한 차이를 보인 반 면, 성문하압은 남성이 여성보다 높은 경향이 있었으나 성별과 연령에서 유의한 차이는 없었다. 본 연구에서 PTF는 선행연구 의 평균호기류율과 마찬가지로 발성을 위한 최소 기류인 PTF 에서 남성이 여성보다 높고 성별에서 유의한 차이를 보였으며, 발성을 위한 최소 압력인 PTP도 남성이 여성에 비해 유의하게 높게 나타났다. 또한 Zraick et al.(2012)의 연구에서는 연령 그룹 범위를 18 39세, 40 59세, 60세 이상으로 나누어 PTP 값을 측 정하였을 때 연령 간 유의한 차이를 발견하지 못하였다. 본 연구 에서는 연령 집단을 20 29세, 30 39세, 40 49세, 50 59세로 더 욱 구체적으로 분류하였는데, Zraick et al.(2012)의 연구와 마 찬가지로 PTF 값이 연령에 유의한 차이를 보이지 않았고 성별 에 따른 차이만을 나타내었다. 본 연구 결과를 통해 PTP와 $\mathrm{PTF}$ 가 연령보다는 성별에 더 민감한 공기역학적 측정치였으 며, 향후 공기역학적 평가를 할 때에 성별에 따른 규준치를 고 려한 음성평가를 해야 할 것이다. 
마지막으로 성별과 연령에 따른 PTW 측정치를 비교했을 때 모든 연령에서 남성의 PTW가 높았으며 연령 $(p<0.01)$ 과 성별 $(p<0.001)$ 에 유의한 차이가 있었다. PTW는 발성 시 필요한 최소한의 기류와 성문하압인 PTF와 PTP를 이용하여 산출해 발성 시 후두의 기류와 압력 특성을 동시에 나타내고 성대병변 과 성대운동장애를 민감하게 반영하는 장점이 있다. 하지만 PTF와 PTP의 영향을 받으므로 만약 두 값 중 하나는 높고 다 른 하나가 낮을 경우 성대의 상태가 정상 범위에 있지 않음에도 정상 수준을 나타낼 수 있으므로(Zhuang et al., 2013), PTW 측 정치만을 비교하기보다는 PTF와 PTP가 각각 어떠한 특성을 보이는지 함께 살펴보는 것이 중요할 것이다.

\section{자극어에 따른 발성역치 측정치 비교}

본 연구에서는 모음에 따른 자극어의 PTP 측정 시 $/ \mathrm{pi} /$ 자 극어에서 $/ \mathrm{pa} /$ 자극어보다 높은 값을 보였고 통계적으로 유의한 차이를 보였다 $(p<0.001)$. 또한 PTW $/ \mathrm{pi} /$ 자극어에서 $/ \mathrm{pa} /$ 자 극어보다 높으며 통계적으로 유의한 차이를 보였다 $(p<0.001)$. 한편 자극어에 따른 강도는 $/ \mathrm{pa} /$ 에서 $/ \mathrm{pi} /$ 보다 높은 강도를 보 였으나 유의한 차이는 보이지 않았다. Aerophone II를 이용한 성문하압 측정의 타당성에 대한 Park et al.(2001)의 선행연구 에 따르면 모음 $/ \mathrm{a} /$ 와 $/ \mathrm{i} /$ 의 변화에 따라 성문하압에 유의한 차 이가 있었고, /ipipi/에서 성문하압은 평균 $6.19 \mathrm{cmH}_{2} \mathrm{O}$, /apapa/ 에서 성문하압은 평균 $4.13 \mathrm{cmH}_{2} \mathrm{O}$ 로 /i/ 모음 환경에서 성문 하압이 더 높게 나타났다. Zhuang et al.(2013) 연구에서도 /pi/ 를 반복하여 PTP를 측정하였는데, 정상인의 경우(평균 38세), $4.22 \mathrm{cmH}_{2} \mathrm{O}$ 로 나타난 반면, 본 연구에서는 $/ \mathrm{pa} /$ 를 사용하여 $\mathrm{PTP}$ 를 측정하였는데 성인 남성의 PTP 값은 3.851( \pm 0.959) $\mathrm{cmH}_{2} \mathrm{O}$, 여성은 3.538( \pm 0.466) $\mathrm{cmH}_{2} \mathrm{O}$ 로 본 연구에서의 PTP 측정치가 더 낮게 나타났다. 이는 /pi:pi:pi:pi:pi:/ 반복 시 /i/ 모 음은 장모음인 긴장성 모음으로 이완성 모음인 /a/ 모음에 비 해 가장 작은 소리로 말하는 데 더 노력성 발성을 했을 가능성 이 있으며, 이러한 이유로 더 높은 발성역치압력을 보이는 것으 로 사료된다. 또한 Lee \& Yoon(2016)의 연구에서는 서울 코퍼 스 20대 남성을 대상으로 voice onset times (VOTs)를 연구하 였는데, $/ \mathrm{a} /$ 모음보다는 /i/나 /u/와 같은 고모음에서 VOT가 상 대적으로 길게 나타났는데, 이는 파열음 개시 후 성대 내전하는 데 걸리는 시간이 길어지므로 성대를 부드럽게 접촉하는 데 더 많은 노력을 기울일 수 있을 것으로 추측된다. 본 연구에서도 $\mathrm{PAS}$ 를 이용하여 자극어에 따른 PTP와 PTW, 강도를 측정 비 교해 본 결과 선행연구와 마찬가지로 자극어 모음에 따라 유의 한 차이가 나타났다. 따라서 임상에서 PAS를 이용하여 평가를 할 때에 사용된 자극어 선택에 유의하여 정확한 방법을 사용 한 평가를 해야 할 것이다.

본 연구는 최근 정상 음성과 장애 음성 판별에 가장 민감한 지표로 보고되는 발성역치 측정치에 대한 한국 정상 성인의 규 준치 마련을 위한 예비연구로서, 공기역학적 검사 시 사용되는 자극어 선택에 대한 증거를 제공하는 데 의의가 있다. 또한 정 상 성인에서도 성별과 자극어에 따라 발성역치 측정치가 유의 미한 차이를 보이므로, 성별과 자극어에 따라 발성역치 측정치 의 정상 규준치가 달라질 수 있음을 시사하였다. 본 연구의 제 한점 및 후속연구를 위한 제안은 다음과 같다.

본 연구에서는 20 50대의 정상 성인을 대상으로 발성역치 측정치를 조사하였으나, 각 연령당 30명씩 적은 수를 대상으로 예비연구를 실시하였다. 추후 연구에서는 성별 및 연령별 모집 단의 특성을 반영할 수 있도록 좀 더 많은 사람을 대상으로 하 여 본 연구의 발성역치 측정치의 정상 규준치를 마련해야 할 것 이다. 아울러 추후의 연구에서는 60 대 이상의 노인층을 대상으 로 발성역치 측정치에 대한 연구가 확대되어야 할 것이다. 둘째, 공기역학적 평가의 궁극적인 목표는 발성 중 공기를 얼마나 효 율적으로 잘 사용하는지 후두 밸브 작용에 대해 알아보는 것 이며, 음성치료의 목표 또한 음성효율성을 높이는 것이다. 음성 효율은 강도를 압력으로 나눈 것으로, 본 연구의 결과를 종합 해 보았을 때 음성효율성에서도 자극어에 따른 차이가 있을 것 으로 예상되므로 후속연구에서는 자극어에 따른 음성효율 측 정치도 함께 연구해 보아야 할 것이다.

중심 단어 : 발성역치기류·발성역치압력·발성역치력·연령·성별.

\section{Ethical Statement}

This study was approved by the Institutional Review Board of Daegu Catholic University (IRB \# CUIRB-2017-0014).

\section{Acknowledgments}

The authors would like to thank all participants.

\section{Declaration of Conflicting Interests}

There are no conflict interests.

\section{Funding}

N/A

\section{Author Contributions}

All authors contributed equally to this work. J.P. designed and performed experiments, analyzed data, and wrote the paper; S.C. designed and performed experiments in the clinic; S.C., C.C., and K.L. provided statistical analysis and critical revision; Also, the authors discussed the results together and implications and commented on the manuscript at each stage.

\section{ORCID iDs}

Ju Eun Park

Seong Hee Choi https://orcid.org/0000-0002-2800-5714

https://orcid.org/0000-0003-2365-6187 


\section{REFERENCES}

Choi, H. S., Lee, J. H., Kim, I. S., Koh, Y. W., Oh, J. S., Bae, J. H., et al. (2000). The acoustic and aerodynamic aspects of patients with spasmodic dysphonia. Journal of The Korean Society of Laryngology, Phoniatrics and Logopedics, 11(1), 98-103.

Choi, S. H. \& Choi, C. H. (2014). The comparison of aerodynamic measures in Korean stop consonants based on phonation types. Phonetics and Speech Sciences, 6(4), 195-203.

Choi, S. H., Jiang, J. J., Yun, B. R., Lee, J. Y., Lim, S. E., \& Choi, H. S. (2010). Phonation threshold flow and phonation threshold pressure in patients with adductor spasmodic dysphonia. Journal of the Korean Society of Speech Sciences, 2(3), 157-164.

Goozée, J. V., Murdoch, B. E., Theodoros, D. G., \& Thompson, E. C. (1998). The effects of age and gender on laryngeal aerodynamics. International Journal of Language and Communication Disorders, 33(2), 221-238.

Jiang, J. J. \& Tao, C. (2007). The minimum glottal airflow to initiate vocal fold oscillation. Journal of the Acoustical Society of America, 121(5), 28732881.

Kim, J. (2014). Korean adult normative data for the KayPENTAX Phonatory Aerodynamic System model 6600. Journal of the Korean Society of Speech Sciences, 6(1), 105-117.

Kim, S. W., Kim, H. H., Park, E. S., \& Choi, H. S. (2010). Acoustic characteristics of normal healthy Koreans with advancing age. Journal of the Korean Society of Speech Sciences, 2(4), 19-28.

Lee, C. Y., An, S. Y., Chang, H., Jeong, H. S., \& Son, H. Y. (2015a). Aerodynamic features and voice therapy interventions of functional voice disorder after thyroidectomy. Journal of The Korean Society of Laryngology, Phoniatrics and Logopedics, 26(1), 25-33.

Lee, D. H., Kim, J. O., Oh, J. K., \& Choi, H. S. (2015b). Comparison of pre and post-operational phonatory aerodynamic parameters in vocal polyp and vocal cord palsy patients. Journal of The Korean Society of Laryngology, Phoniatrics and Logopedics, 26(2), 112-116.

Lee. I., Yun, J., \& Hwang, Y. (2013). A study on the characteristics of phonation threshold pressure and phonation threshold airflow of patients with functional voice disorder. Phonetics and Speech Sciences, 5(1), 6369.

Lee, J. H., Park, E. H., Chung, S. M., \& Kim, H. S. (2008). Change of voice during menstrual cycle. Journal of The Korean Society of Laryngology, Phoniatrics and Logopedics, 19(2), 113-116.

Lee, Y. \& Yoon, K. (2016). A study on the voice onset times of the Seoul Corpus males in their twenties. Phonetics and Speech Sciences, 8(4), 1-8.
Park, S. H., Jeong, O. R., \& Seok, D. I. (2001). The validity analysis between measurement method of subglottic air pressure. Phonetics and Speech Sciences, 8(3), 201-208.

Patel, R. R., Awan, S. N., Barkmeier-Kraemer, J., Courey, M., Deliyski, D., Eadie, T., et al. (2018). Recommended protocols for instrumental assessment of voice: American Speech-Language-Hearing Association expert panel to develop a protocol for instrumental assessment of vocal function. American Journal of Speech-Language Pathology, 27(3), 887-905.

Suh, J. S., Song, S. Y., Cheong, Y. S., Kim, J. S., Chi, D. H., \& Lee, M. K. (1999). Aerodynamic study in normal Korean and patients with vocal polyp. Journal of The Korean Society of Laryngology, Phoniatrics and Logopedics, 10(1), 5-11.

Suh, J. S., Song, S. Y., Kwon, O. C., Kim, J. W., Lee, H. K., \& Jeong, O. R. (1997). Mean value of aerodynamic study in normal Korean. Journal of The Korean Society of Laryngology, Phoniatrics and Logopedics, 8(1), 2732.

Suh, W. J., Hong, Y. H., Choi, J. M., Jung, E. J., Sung, M. W., Kim, K. H., et al. (2006). Clinical characteristics of functional dysphonia. Journal of Korean Society of Laryngology, Phoniatrics and Logopedics, 17(2), 127132.

Titze, I. R. (1988). The physics of small-amplitude oscillation of the vocal folds. Journal of the Acoustical Society of America, 83(4), 1536-1552.

Titze, I. R. (1992). Phonation threshold pressure: A missing link in glottal aerodynamics. Journal of the Acoustical Society of America, 91(5), 29262935.

Van den Berg, J. (1958). Myoelastic-aerodynamic theory of voice production. Journal of Speech and Hearing Research, 1(3), 227-244.

Zheng, Y. Q., Zhang, B. R., Su, W. Y., Gong, J., Yuan, M. Q., Ding, Y. L., et al. (2012). Laryngeal aerodynamic analysis in assisting with the diagnosis of muscle tension dysphonia. Journal of Voice, 26(2), 177-181.

Zhuang, P., Sprecher, A. J., Hoffman, M. R., Zhang, Y., Fourakis, M., Jiang, J. J., et al. (2009). Phonation threshold flow measurements in normal and pathological phonation. Laryngoscope, 119(4), 811-815.

Zhuang, P., Swinarska, J. T., Robieux, C. F., Hoffman, M. R., Lin, S., \& Jiang, J. J. (2013). Measurement of phonation threshold power in normal and disordered voice production. Annals of Otology, Rhinology and Laryngology, 122(9), 555-560.

Zraick, R. I., Smith-Olinde, L., \& Shotts, L. L. (2012). Adult normative data for the KayPENTAX phonatory aerodynamic system model 6600. Journal of Voice, 26(2), 164-176. 